Tropelías. Revista de Teoría de la Literatura y Literatura Comparada, 19 (2013)

Imaginar, escribir. La imaginación lingüística en J. Joyce y P. Celan...

\title{
IMAGINAR, ESCRIBIR. LA IMAGINACIÓN LINGÜÍSTICA EN J. JOYCE Y P. CELAN, A TRAVÉS DE NIETZSCHE
}

Noelia BILLI

Universidad de Buenos Aires

\section{Imaginar}

i bien el imaginar no es algo novedoso -por cuanto ha sido conceptualizado S desde el inicio de lo que reconocemos como tradición occidental (es decir, desde Platón)-, sí es cierto que a través de las épocas se ha transformado lo suficiente como para dar lugar a problematizaciones nuevas en distintos ámbitos. Durante el siglo XX, la imaginación tuvo un lugar privilegiado en los debates conceptuales en torno a su incidencia en las escrituras literarias, filosóficas, psicoanalíticas y políticas, entre otras. Dicha posición destacada tiene mucho que ver con la puesta en cuestión de ciertas bases que hasta el momento habían sostenido a Occidente, pues con la sospecha asediando otras facultades de lo humano (la sospechosa pureza de la razón y de la percepción), la imaginación pudo desprenderse relativamente de la subordinación a la que siempre estuvo sometida. Liberada hasta cierto punto del yugo del logos occidental, la capacidad imaginante se revela como un operador conceptual fructífero para captar algunas dinámicas vigentes en la época en que lo humano (me refiero al así llamado «humanismo» cuya «imaginación» no es la que aquí se está proponiendo) ya no alcanza a dar cuenta de lo que acontece en el mundo. En este trabajo voy a sostener que a fin de aprehender la potencia insurgente de ciertas escrituras (narrativas y poéticas) es preciso trabajar con una noción de «imaginación» que ya no dependa de las grillas de inteligibilidad tradicionalmente modernas (básicamente, la imaginación como facultad representativa de una conciencia subjetiva intencional), pues sólo así ella puede ser asociada a la lengua y revelar las torsiones textuales que pueden resultar de dicha «imaginación lingüística». En principio, haré un breve recorrido por algunas de las nociones occidentales que resultan problematizadas durante el siglo veinte, toda vez que 
es a partir del espacio abierto por estos interrogantes que la imaginación emerge como vector de producción de lenguajes insurrectos. Para ello, tomaré como hilo conductor algunas objeciones a la metafísica moderna occidental introducidas por el pensador alemán F. Nietzsche. Luego, trataré de mostrar cómo dos modos escriturales que, en primera instancia, parecen bastante disímiles (las escrituras de James Joyce y de Paul Celan), pueden estudiarse como ejercicios de la imaginación lingüística.

\section{Un martillo pende sobre el siglo veinte...}

Durante el siglo veinte comenzaron a escucharse los ecos de aquel martillo nietzscheano $^{1}$ que -a fines del siglo anterior- evidenciaba que Occidente no era algo distinto a un edificio mal construido, roído por las fisuras y cuya clausura preventiva sería útil para ahorrarnos algunos accidentes desagradables. El diagnóstico del pensador alemán se apuntalaba en la visible decadencia de un cierto personaje moderno, el así llamado «sujeto de la conciencia», y una de las cosas más llamativas de su planteo era -y sigue siendo- que la mayor parte de su operación conceptual sobre la metafísica moderna tomaba fuerza en una crítica de las concepciones del lenguaje y su relación con el mundo. Adelantando en parte lo que sería conocido más tarde como el «giro lingüístico» en el pensamiento (filosófico, pero también antropológico, psicoanalítico, etc.), la batalla nietzscheana supuso llevar al frente de la escena una problemática que ya recorría, por cierto, la obra artística de muchos actores culturales (al menos, europeos $^{2}$ ): las unidades del lenguaje parecían estar inmersas en un movimiento centrífugo respecto de todo centro organizador, ya sea un lenguaje total, un sujeto intencional o bien una nación en la cual asentar un modo de vida. Fuga aparentemente desatada por el naufragio de las nociones que hacían de hilo conductor de una realidad, por otra parte, crecientemente caótica. Creo que un breve recorrido por los restos de este naufragio es imprescindible a fin de concebir en toda su potencia la eclosión de la imaginación lingüística en la literatura.

\footnotetext{
${ }^{1}$ El motivo del «martillo» en el pensamiento nietzscheano es muy conocido. Su explicitación puede hallarse, por ejemplo, en Crepúsculo de los ídolos. Cómo se filosofa con el martillo (1889), como se adelanta ya desde el subtítulo.

${ }^{2}$ Pienso principalmente en lo que se conoce como la «Viena de fin de siglo», terreno privilegiado para indagaciones en torno a la problematización del lenguaje «humanista» (de todo lenguaje: literario, pictórico, arquitectónico, etc.). De allí que muchos pensadores contemporáneos retornen a las obras del más extravagante imperio crepuscular de la mittel-Europa. M. Cacciari ha escrito un libro que recorre el arte vienés con énfasis nietzscheano, se trata de Hombres Póstumos: la cultura vienesa del primer novecientos (1980). Para un panorama de la enorme variedad de perspectivas que allí encuentran un punto de convergencia, resulta indispensable la compilación de textos realizada por Casullo (1990).
} 
Tropelías. Revista de Teoría de la Literatura y Literatura Comparada, 19 (2013)

Imaginar, escribir. La imaginación lingüística en J. Joyce y P. Celan...

\section{Nietzsche, el lenguaje y la verdad de las metáforas}

En Más allá del bien y del mal, Nietzsche señalaba el «hechizo invisible» que explica «parecidos de familia» entre diferentes pensadores: la común filosofía de la gramática, el dominio y la dirección inconscientes ejercidos por las relaciones establecidas entre las palabras de una lengua. La puesta en primer plano de la potencia del lenguaje anida en el seno de un malestar ingobernable: la gramática moderna, que conduce a postular a un «sujeto uno» como fuente de toda actividad, no parece ser ya de alguna utilidad. La configuración actual del mundo pone en entredicho ese sujeto del enunciado que estructuró toda una metafísica, sujeto que se revela como la insostenible hipótesis de existencia de una voluntad personal que primero intenciona, piensa, y luego se plasma en el mundo mediante actos cuyo sentido propio le está reservado de forma exclusiva. Tal sujeto propietario (de sí, de sus pensamientos y acciones) habrá sido considerado una entidad sustancial y, en tanto tal, un ser cuya esencia única y eterna funciona como principio unitivo de un elenco de atributos fijos que se relacionan con el núcleo sustancial de modo necesario. El hombre así configurado se recorta de la superficie del mundo y se pone frente a él: es el sujeto que sólo concibe lo otro de sí como objetos capturables a través de la mirada que se detiene en la escena representativa que se juega en la conciencia personal. Lo otro de sí: objetos que, no importa cuán cerca aparenten estar, siempre se hallan al otro lado de un espacio que se tornará más y más difícil de franquear, toda vez que el único acceso que el hombre tiene es mediato: imágenes, conceptos, otros tantos nombres de las representaciones. Para este hombre, que sólo conoce el mundo bajo la forma apropiadora y reductiva que supone la imagen especular que únicamente se da en el ámbito de la intimidad del sujeto consigo mismo, el lenguaje no puede sino funcionar como una herramienta de mera expresión de su pensamiento o voluntad, apta (en el mejor de los casos) para comunicar a otros como él sus representaciones. En tanto herramienta inerte al servicio de un pensamiento que se constituye en otro ámbito -anterior e independiente del lingüístico-, el sentido propio de cada palabra de este lenguaje quedará dentro de la esfera de las propiedades del hombre. En efecto, no podría ser de otro modo, tratándose de una gramática que toma forma en el dispositivo representativo moderno y que funciona de acuerdo al par binario significante-significado, según el cual a cada palabra le corresponde designar un contenido representativo, imagen especular de la realidad cuya génesis debe buscarse en los procesos cognoscitivos del hombre. El hombre conoce, esto es, genera una red de palabras que se superpone palmo a palmo a una realidad representada, y a esa superposición (al lazo seguro, firme e indestructible) de las 
palabras y las cosas la llama verdad ${ }^{3}$. No obstante, el hombre -seguro como está de retener el sentido de sus propias palabras- podrá entregarse al juego de los desplazamientos de sentido, dará al lenguaje también un giro metafórico que le permitirá «adornar»su pensamiento, hacerlo más atractivo y persuasivo para sus pares. El carácter metafórico del lenguaje quedará, para la tradición, relegado a la faz ornamental, superfluo velo que podrá rasgarse cuando el celo del conocimiento riguroso lo exija, cuando lo requerido sea la Verdad desnuda.

En un escrito temprano ${ }^{4}$, Nietzsche introduce graves objeciones a las nociones recién resumidas del lenguaje. Enfatizando el carácter convencional de la designación lingüística, plantea un mundo de «esencias primitivas» (entidades totalmente inalcanzables para el hombre) al cual no se accede sino a través de metáforas. Mediante una operación semejante, Nietzsche pone a la metáfora en el origen del lenguaje y de toda actividad cognoscitiva, pero ¿qué supone este desplazamiento? Si se concibe a la metáfora como una extrapolación analógica arbitraria entre diferentes niveles de realidad, lo que el pensador alemán pone en primer plano es el carácter ficticio de lo que se ha llamado conocimiento. Ficciones que, ciertamente, tienen su utilidad: el hombre, dice Nietzsche,

\begin{abstract}
desea existir en sociedad y gregariamente, precisa de un tratado de paz y, de acuerdo con éste, procura que, al menos, desaparezca de su mundo el más grande bellum omnium contra omnes. [...] En este mismo momento se fija lo que a partir de entonces ha de ser «verdad», es decir, se ha inventado una designación de las cosas uniformemente válida y obligatoria, y el poder legislativo del lenguaje proporciona también las primeras leyes de verdad (Nietzsche, 1873: 13).
\end{abstract}

Si miramos lejos en el horizonte, las consecuencias de una afirmación como ésta hacen temblar los cimientos del pensamiento moderno: el hecho de que el conocimiento no sea sino una ficción (útil o no), que incluso el lenguaje que se pretende riguroso (i. e. el científico) no sea otra cosa que metáforas bien formadas, y sobre todo si se prestan oídos a esa «denuncia» acerca del «poder legislativo» que tendría todo lenguaje, entonces debe decirse que los criterios de demarcación que sostienen a la metafísica moderna son un tejido en descomposición, cuyo hedor contamina toda jerarquía que hasta el momento se haya querido establecer entre distintos ámbitos de experiencia.

La problematización del lenguaje también tiene una estrecha relación con la constatación, por parte de Nietzsche, de la «muerte de Dios». Más allá de las formas que lo divino ha podido tomar en el interior de las diversas doctrinas onto-teológicas, en

\footnotetext{
${ }^{3}$ Obviamente, esta es una versión de lo que es la verdad, conocida como «verdad como correspondencia». Para su despliegue y problematización en la historia, véase Foucault (1966).

${ }^{4}$ Cfr. Nietzsche (1873).
} 
todas ellas Dios ha funcionado como el garante de la Verdad, su fundamento, su condición de posibilidad «moral» para el hombre (es decir, el hecho de que la Verdad y su búsqueda sea concebido como algo valioso, que vale la pena y que moviliza todos los recursos que el hombre pueda poner a su disposición). Mediante su operar, Dios no solamente asegura que el mundo tienen un orden estable sino también que puede ser conocido por el hombre (es decir, que la verdad existe). Tal armonía reside en el hecho de que sea una y misma lógica aquella que rige el orden de las cosas y las investigaciones que sobre ellas se realizan ${ }^{5}$. A su vez, los conocimientos adquiridos, a fin de ser conservados, deberán plasmarse en un lenguaje que se amolde a esta lógica. Esta «razón» ordenadora es lo que se conoce como lógica occidental o discursiva, basada en el principio de no contradicción, estructurada de un modo binario (principio del tercero excluido) y jerarquizante, pero principalmente una lógica que, al ser deductiva, tiene necesidad de enunciados universales, toda vez que es a partir de ellos que puede reducir lo dado a fórmulas que permitan hacer del mundo algo calculable. La presión que ejerce esta lógica hacia la formulación de enunciados onmiabarcativos es evidente si se atiende a los procesos de formación de los conceptos.

\section{El fetichismo en el comercio lingüístico}

La crítica del concepto llevada a término en la obra nietzscheana apunta al reconocimiento de los límites de su vigencia y utilidad, es decir: se trataría de poder tomar al concepto como un acontecer tan fenoménico como el mundo percibido sensorialmente $\mathrm{y}$, de ese modo, poder reconocer tanto en uno como en otro reverberaciones de la superficie única de un mundo sin correlato trascendente, ni como origen ni como causa ni como meta final, es decir, un mundo an-árkhico.

En Crepúsculo de los ídolos, por ejemplo, se identifica al concepto como la pasión de una razón que «fuerza a asignar unidad, identidad, duración, substancia, causa, cosidad, ser», razón esta que nos es desde todo punto de vista necesaria, pero no por eso menos falsa (la obligación de poner bastardillas a 'falsa' proviene de la torsión semántica que este término experimenta: dado que la Verdad como tal -única, inmutable, hallable al final o al principio de algún sendero iluminado- no existe, todo lo que podamos decir es falso. Por supuesto, esto es lo único a lo que podemos aspirar, de modo que el llamado nietzscheano se orienta a rescatar la lucidez que permita afirmar lo falso sin por eso dejar de considerarlo tal). La razón que impulsa la creación conceptual

\footnotetext{
${ }^{5}$ Básteme mencionar a G. W. F. Hegel, culminación de esta línea de pensamiento moderno, para quien sólo hay una lógica y una realidad, que es la del Espíritu o la Idea (que luego se alienan a sí mismas y devienen naturaleza, etc.). Véase Hegel (1807) y para los efectos políticos que esta perspectiva hace posibles, Hegel (1821).
} 
tiene su lugar privilegiado en el lenguaje, es el «supuesto básico de [su] metafísica» (Nietzsche, 1889: 54). Allí logramos entender el alcance que puede tener el desenmascaramiento de la razón en el lenguaje, no tanto porque ésta inventa conceptos para operar en el mundo, sino más bien porque en el mismo movimiento oculta su operar y establece como realmente existentes en todos los planos de lo real estas categorías. «Ese fetichismo [el de la razón] ve en todas partes agentes y acciones: cree que la voluntad es la causa en general; cree en el "yo", cree que el yo es un ser, que el yo es una substancia, y proyecta sobre todas las cosas la creencia en la substancia-yo -así es como crea el concepto “cosa” (Nietzsche, 1889: 54-55; las negritas son mías). Este «fetichismo» supone el tomar un simple ordenamiento contingente, una manera de crear formas y figuras del mundo inteligibles, como si éstas fueran reales, como si estuvieran allí en la realidad esperando ser halladas, como si su ser fuera independiente del lenguaje que lo «encuentra», que lo explica o que lo comunica. Precisamente, la fetichización se da bajo la forma de la denegación del tránsito del lenguaje por las instancias de configuración y reordenamiento ontológicos, de lo cual resulta una ontología de lo Uno, que se concibe como dada de una vez y para siempre. Y son los fetiches (la sustancialización de las ficciones llamadas «Yo», «conciencia», «cosa») los que clausuran la apertura originaria (la ausencia de entidades inmutables, de fundamentos sólidos), que es su condición de posibilidad, pues están allí para suturar esa herida e impedir que nuevas formas advengan ${ }^{6}$. Funcionamiento paradójico: negar la posibilidad de la propia existencia, negar-se en última instancia, socavando las propias bases y llevando así a un movimiento de desfondamiento que no podrá detenerse ante nada.

\section{Lo falso: una perspectiva}

¿Cómo se vive en el mundo de lo falso? En primer lugar, habría que poner en relación esta falsedad con aquella otra noción, la de ficción. A partir de la problematización de la Verdad, toda la red conceptual del error -lo falso-, la ficción, adquiere un estatuto nuevo, por cuanto se arranca del lugar subordinado en que una Certeza, una Verdad o una Realidad la han mantenido. En este arrancarse que invierte, y destruye al mismo tiempo, la jerarquía instituida entre estos pares conceptuales, lo que

\footnotetext{
${ }^{6}$ Puede pensarse, un poco anacrónicamente, cuán sugerente resulta que más tarde, desde la teoría psicoanalítica, precisamente sea el «objeto fetiche» aquello que funcionaría a modo de «tapón» para obturar la falta originaria del aparato psíquico. $\mathrm{Si}$, como en el psicoanálisis, se piensa que el modo de abordar la castración (la ausencia de falo, que no es otra cosa que la falta de completud) define una estructura psíquica, una de los posibles abordajes es «saber» que dicha falta existe pero negarla atribuyendo a un objeto las características de aquello que falta (el falo, la completud). Este objeto, que tiene la función paradójica de ser un saber que sostiene un no-saber, es el fetiche: algo que viene a negar que existe una ausencia, un mecanismo de suplencia, de algún modo.
} 
tiende a suceder es que falta un criterio estable al cual recurrir para hacer diferenciaciones que hasta determinado momento se consideraron básicas y naturales, y que sin embargo se ponen en entredicho.

Todas las zonas ontológicas estructuradas binaria, atributiva y jerárquicamente (y esto es tanto como decir: la metafísica occidental toda) generan necesariamente un criterio que permita demarcar los dos polos del par de opuestos, aquello que permita localizar el polo que se valora positivamente en su pureza, reafirmar sus fronteras y protegerlo de la contaminación de lo otro ${ }^{7}$. Cuando este criterio fundante de las demarcaciones no se halla (o ya no funciona o está loco), lo que sucede es la puesta en evidencia de la originaria contaminación y falta de pureza de todo ámbito. Todo aquello que podía distinguirse según procedimientos más o menos rigurosos, más o menos engorrosos, según métodos que conducían por caminos despejados hasta el claro del bosque, comienza a liberarse de sus estrictas delimitaciones. Las fronteras se hacen porosas y habilitan una ósmosis que tiende a diseminar en todas direcciones las propiedades de lo que es. A partir de allí no será del todo seguro marcar los límites de las identidades, lo mismo y lo otro ya no serán instancias contrarias y excluyentes recíprocamente, la mezcla será lo que domine la escena, tanto como la sospecha de que el modo en que entendemos lo que hay frente a nosotros podría ser diferente, y ello no en desmedro de nuestra capacidad de conocer, sino más bien teniendo en cuenta que lo que puede de ahora en más llamarse «conocimiento» (y quizás, nunca se trató de otra cosa) es una configuración posible a partir de un recorte de parte de lo real.

Podría decirse que lo que pulsa en cada una de las expresiones del mundo (una palabra, una voz, un gesto) es un movimiento de emancipación, una fuerza que debilita los anudamientos que durante siglos mantuvieron unidos a la Verdad con la realidad, con el concepto, con la lógica deductiva. Como partes intercambiables y capaces de tomar un lugar en otras configuraciones, se verá a cada una de estas nociones adquirir un significado y una función no ya de acuerdo a alguna propiedad intrínseca o esencial, sino a su posición en una constelación que supone una práctica discursiva y un proceso de interpretación de la realidad: en suma, a una perspectiva.

\section{La imaginación como potencia no-humana}

El modo de subjetivación moderno (la máquina antropológica que produce un individuo propietario cuyo punto cúlmine de autonomía se encuentra en el «yo», fundamento del imperio de lo propio) que da lugar al «humanismo», se pone en

\footnotetext{
${ }^{7}$ El criterio sería, en términos de G. Deleuze, lo que se utiliza para elegir entre los pretendientes. Véase Deleuze (1969: 180-188).
} 
entredicho de manera radical desde esta perspectiva. Principalmente, allí donde la construcción humanista se fundaba en la hegemonía de la conciencia y de la voluntad sobre todo lo real, donde confiaba en el poder humano sobre las circunstancias externas (presuponiendo, es obvio, que el hombre era una partícula errante y solitaria, enfrentada al mundo de las cosas y de los otros hombres, mundo extraño y amenazante). Sin embargo, todo parece indicar que la figura del «hombre» es una ficción entre otras (la ficción principal de la imaginación humanista) y que la subjetividad es parte de un proceso más amplio, un punto de adensamiento que se da de forma provisoria en un cruce contingente de distintas líneas de fuerza (cfr. Cragnolini, 1998). El imperio del hombre sobre la realidad no puede ser sostenido sino ignorando toda una serie de dinámicas (culturales, políticas, lingüísticas, económicas, deseantes, etc.) que lo exceden completamente y de las cuales es en realidad un efecto, un producto, un resultado. Así pues, el «yo», la «conciencia» y su «voluntad» ya no estarán en el principio que funda el sentido, que inaugura la sede de la verdad, que conoce con certeza, sino más bien en las zonas marginales de la experiencia, como un subproducto aleatorio e incluso prescindible de un mundo misterioso que se fuga hacia lo ignoto permanentemente. Si bien esta perspectiva ha resultado desalentadora para quienes sólo pueden concebir el mundo bajo la forma de un edificio de sólidos cimientos, otras miradas se han sobrepuesto al desasosiego inicial (el que adviene junto a la evidencia de la falta de fundamentos de todo lo que es), en la tentativa de explorar los nuevos territorios abiertos a la experiencia. Sobre todo en las artes (tanto las escriturales como las plásticas) lo que se trasluce es la inquietud por renovar los modos de acceso al mundo, por indagar en la noción misma de experiencia cuando el sujeto pierde su lugar central (¿Qué se experimenta? ¿Quién experimenta? ¿Es la experiencia un proceso activado por el sujeto o bien un pathos al que se está sometido y que adquiere un poder constitutivo sobre la subjetividad?).

Con la ruptura del eje humanista -que supone el desplazamiento de la conciencia racional del lugar constituyente y fundante de lo real- una de las fuerzas que afloran es la de lo imaginario (fuerza «no-humana», entonces). Es en el siglo veinte que la imaginación comienza a ser invocada para explicar toda clase de fenómenos sociales, políticos y literarios. Desde las nociones más «sociológicas» de imaginación (como la trabajada, por ejemplo, por Benedict Anderson en su ya clásico Comunidades imaginadas, donde la imaginación tiene mucho que ver con la pérdida de las bases materiales de las relaciones sociales), hasta aquellas que toman la imaginación como un concepto ontológico (es decir, de creación en sentido fuerte, invención de ser) a partir del cual organizar una descripción de la vida social y al mismo tiempo una estrategia 
política revolucionaria (es el caso de la monumental obra de Cornelius Castoriadis ${ }^{8}$ ). En lo referente al lenguaje, pensarlo desde la referencia imaginaria supone, por una parte, cargarlo de la potencia creadora e instituyente que la imaginación conlleva durante el siglo XX. Es decir que cuando menciono la imaginación lingüística uno de los primeros sentidos a los que apunto es a la institución de modos de ser, hacer y sentir mediante el lenguaje. Esto es tanto como rechazar el carácter descriptivo de la lengua (aspecto privilegiado por la metafísica moderna) a fin de destacar su potencia productiva nohumana.

\section{La imaginación lingüística: contra las interpretaciones «decadentes»9}

Es importante realizar dos aclaraciones que, discutiendo con ciertas interpretaciones comunes de la «imaginación lingüística», esclarecerán la orientación que aquí doy a esta noción.

En primera instancia, una concepción como esta del lenguaje y la imaginación no implica de ningún modo un intento de «devolver» la agencia al hombre, agencia que parece haber perdido durante el siglo pasado: concebir que la realidad se sostiene en tramas lingüísticas imaginarias ubica al sujeto como parte de un proceso del cual será, en última instancia, un efecto. Aquellas interpretaciones que sostienen que localizar una potencia ontológica en el lenguaje y en la imaginación conlleva la postulación necesaria de un sujeto que intenciona ese lenguaje y que tiene como facultad esa imaginación, simplemente no entiende que cuando el lenguaje toma un lugar constituyente el único sujeto que puede ser concebido es un «resto» de sujeto cuyo rasgo más relevante sería la pasividad ante la lengua que lo habla y la imaginación que lo crea $^{10}$. Estas interpretaciones son comunes en los modos de pensamiento que buscan una restauración de ciertos valores modernos en torno al uso del lenguaje como herramienta humana de operación sobre el mundo ${ }^{11}$, y que por eso son incapaces de comprender la asignación de potencias a los aspectos no humanos del mundo circundante.

Por otro lado, y recurrentemente desde algunas izquierdas que invocan el materialismo como punta de lanza de la transformación socio-política, la concepción

\footnotetext{
${ }^{8}$ En principio, puede consultarse la obra fundamental del autor, Castoriadis (1975).

${ }^{9}$ Doy aquí a «decadente» el sentido nietzscheano, es decir, el de aquello que todavía es solidario de una metafísica perimida porque no puede -fisiológicamente hablando- digerir la «muerte de dios» (y, consecuentemente, la del hombre).

${ }^{10}$ Por supuesto, el sujeto no ha desaparecido, y es improbable que lo haga alguna vez. Ningún pensador serio (Foucault, Deleuze, Derrida y tantos otros tan injustamente acusados...) ha confundido tan obstinadamente como los «decadentes» (cf. nota anterior) «hombre», «sujeto» y «sujeto constituyente». Para el tema del «resto» tal como aquí se utiliza, véase Cragnolini (2008).

${ }^{11}$ Un caso paradigmático resulta el de J. Habermas con su Teoría de la acción comunicativa (del autor véase, entre otros, Habermas, 1981).
} 
que aquí trabajo de «imaginación lingüística» es criticada por entender que se trata de un giro «idealista» de la filosofía (o, directamente, una «continuación» del idealismo moderno que se oculta tras la ilusión de ser revulsivo para esta misma tradición). Estos modos de la crítica se obstinan, por lo general, en sostener un binarismo -ya ciertamente obsoleto- entre la materialidad de lo real y los modos de representarla (y esto en todas sus variantes: binarismos entre forma y contenido, entre verdad e ideología, etc.). Sólo que, si se acepta el diagnóstico inicial acerca de la ruptura de las referencias a la verdad y la conciencia dadas al inicio, este par binario es insostenible (al igual, por otro lado, que toda la metafísica de lo binario). Si para estos críticos nada de lo que suceda en el ámbito del lenguaje puede afectar lo real (y menos aún cuando el lenguaje está asociado a lo imaginario), es porque ellos precisan pensar al lenguaje como red ideal con la que se cubre la realidad material. Muy lejos de ello, y de algún modo inscripta en el linaje nietzscheano, aquí se utiliza la «imaginación lingüística» como vector de profundización del materialismo, esto es: una vez que la lengua es sacada de la torre de marfil en donde convivía con el sujeto moderno y desde la cual se mantenía pura del contagio de lo real, ella incide (corta, rasga y nunca deja cicatrizar) en el tejido de lo concreto de un modo antes imposible de concebir. El ámbito lingüístico adquiere un espesor lo suficientemente consistente como para tallar la realidad sin tregua ${ }^{12}$.

De manera que con «imaginación lingüística» hago uso de un concepto que atiende a la materialidad ganada por el lenguaje, a partir de la cual interviene lo real con una potencia creativa que no precisa de un sujeto sino que, antes bien, da lugar al acontecer de diferentes subjetividades que se disputarán el mundo (es decir, a la política).

\section{Escribir}

\section{La lengua extraña}

Las escrituras de James Joyce y Paul Celan son superficies privilegiadas para trabajar desde la perspectiva de la imaginación lingüística, dado que en ellas es la lengua misma la que es expuesta a los avatares de una imaginación enloquecida por escapar de los límites impuestos por el «enemigo». De hecho, si utilizo aquí esta palabra es porque tanto en uno como en el otro, la lengua deviene el campo de batalla en el que se estrategizan ataques y resistencias a quien es percibido (no sin razón) como el opresor.

\footnotetext{
${ }^{12}$ La palabra que rompe los límites impuestos por el idealismo lingüístico y se toca con la materia era escrita por Celan en Reviste las cavidades de la palabra: «Reviste las cavidades de la palabra / con pieles de pantera, // amplíalas, piel para allá, piel para acá, / sentido para allá, sentido para acá, // dale aurículas, ventrículos, válvulas / y soledumbres, parietales...» (Celan, 1983).
} 
Imaginar, escribir. La imaginación lingüística en J. Joyce y P. Celan...

James Joyce, el escritor, y Paul Celan, el poeta, habitaban los márgenes, pertenecían a minorías políticas de las sociedades por las que circularon. Sin embargo, no abandonan ni condenan a un improbable olvido a las lenguas y culturas literarias mayores, sino que se sitúan en una posición de extraterritorialidad respecto de ellas. Esta especie de ajenidad vivida desde el interior -de allí que no se confunda con «estar fuera»-, permitió a la imaginación un espaciamiento linguiístico, es decir: en ellos, la imaginación lingüística implica cada vez la creación de un lugar o emplazamiento para el excluido desde el cual éste opera como un magnetizador ${ }^{13}$ de las fuerzas disgregantes y delirantes que recorren las «identidades» nacionales y de la lengua.

James Joyce nació en Dublín, Irlanda, en 1882. Su confesión era la católica; su idioma, un inglés de olvidado acento irlandés. Él vivía la extensión de las redes de la Inglaterra imperial a través de la lengua (el inglés británico) y las formas narrativas victorianas, las cuales no sólo eran vehículo sino también instrumento de la opresión y dominación de la cultura irlandesa en la medida en que el inglés británico se erigía en idioma oficial: sucede que toda lengua que se pretende una e intenta barrer con la multiplicidad lleva en sí el carácter del Amo (volveré a ello).

Por su parte, el poeta Paul Celan vio la luz por vez primera en el año 1920. De origen rumano y familia judía, escribió siempre en alemán, aun si en la región donde nació y creció (la Bucovina) se hablan al menos cuatro lenguas, sin contar el yiddish. Después de la muerte masiva que el nazismo prodigó a todo aquello que no fuera ario -personas judías y gitanos, pero también sus lenguas, espacio de despliegue de sus tradiciones y modos de vida-, correlativa de una exaltación falaz de todo lo alemán, Celan se declara incapaz de escribir en rumano, aun habiendo sufrido la pérdida de sus padres en campos de exterminio nazis, aun si la lengua germánica quedaba marcada por el exterminador.

De manera que tanto el uno como el otro se encuentran en la situación de escribir en una lengua que no les es «propia». Si bien puede decirse que una lengua nunca es «propia» ${ }^{14}$, es cierto que ciertas posiciones en el campo social lo hacen más o menos evidente. Cuando el Amo (el inglés o el alemán) se inscribe en ella y reclama un derecho de uso hegemónico, aquellos que son excluidos no pueden eludir la percepción de la inapropiabilidad de la lengua. En razón de ello, son sus testimonios (imposibles, como

\footnotetext{
${ }^{13}$ La idea del «magnetizador» (o «imán») de las fuerzas que, en última instancia, tiene un operar «deconstructivo» la extraigo de una serie narrativa del escritor polaco Bruno Schulz, compuesta por los relatos «Agosto», «Visitación», «Los pájaros», «Los maniquíes», «Tratado de maniquíes o el segundo Libro del Génesis», «Tratado de maniquíes (continuación)» y «Tratado de Maniquíes (conclusión)». Cfr. Schulz (1933: 45-88).

${ }^{14}$ En torno a esta temática gira el ensayo de Derrida (1996a). El filósofo argelino trabaja el despliegue a partir del siguiente pensamiento: «No tengo más que una lengua, no es la mía».
} 
el de todo aquel que está privado de una palabra «propia») los que constituyen la punta de lanza de una experiencia que, en rigor, puede generalizarse: la sensación de extrañeza respecto de la lengua que se usa se revelará no como un «resultado» al cual llegar luego de disquisiciones filosóficas ni como algo exclusivo de los que escriben en una lengua que no es la así llamada «lengua materna», sino antes bien como un «dato» para las subjetividades del siglo $\mathrm{XX}^{15}$. Esta situación coincide $-\mathrm{y}$ no se trata de un azarcon el desdibujamiento del Estado-nación típicamente moderno, uno de los primeros y más acuciantes signos de la descomposición de la estatalidad en la época de la globalización. Si bien no discuto la posibilidad de que la globalización podría implicar la subversión de ciertas jerarquías asentadas en las nociones de «lo nacional» y «lo autóctono» (en la medida en que auspicia las heterotopías, profusión de lugares irreductibles a un solo trazado relacional, histórico o social; aunque estaría tentada a llamar a eso «mundialización» ${ }^{16}$ ), ello sólo será pensable en mayor medida a partir de los años 70. Las zonas más tempranas del siglo veinte (en las cuales inscriben sus prácticas Joyce y Celan) aun se definían en torno a la nacionalidad, por lo cual la reacción de los nacionalismos conservadores por generar y preservar una supuesta «pureza» de la raza, la nación y la lengua describe la sintomatología de la «descomposición» de lo nacional. Desde esta perspectiva leo las escrituras tanto de Joyce como de Celan, a modo de estrategias más acordes con los tiempos por venir (nuestra época, por caso) para luchar contra esta reacción conservadora que aun buscaba en la solidez del idioma los cimientos de un estado, pues la imaginación que domina sus escrituras permite localizar en la lengua uno de los vectores de desagregación de la materia «nacional».

\section{Imaginar un territorio}

Retornando a lo específico de las escrituras de James Joyce y de Paul Celan, antes decía que, en lugar de rechazar de plano el uso de la lengua y literatura (inglesa y alemana) como tales, ellos estrategizan un uso de las mismas que las asedia desde el interior. Teniendo en cuenta que las minorías pelean, en el mismo territorio que las

\footnotetext{
${ }^{15}$ Acerca de la imposibilidad del testimonio y su relación con el vaciamiento de la «experiencia», varios pensadores han encontrado algo para decir a partir, principalmente, de los textos publicados por Primo Levi después de su estadía en los campos nazis. Jacques Derrida trabaja específicamente el tema, y relacionado con la poesía de Celan, en una conferencia dictada en Buenos Aires (véase Derrida, 1996b). Además de lo que a esta altura es una referencia obvia de la lectura derridiana sobre el tema: Derrida (1986). G. Agamben también ha escrito algunas páginas de gran resonancia con el tema aquí tocado, véase Agamben (1998). Por último, ciertos textos de M. Blanchot podrían leerse a su vez desde este encuadre (cfr. Blanchot, 1994).

${ }^{16}$ El concepto de heterotopía se hace significativo para el pensamiento contemporáneo en los análisis de M. Foucault (cfr. Foucault, 1967). Por otra parte, asocio la «heterotopía» a un cierto modo de abordar la contemporaneidad como «mundialización» por parte del filósofo Jean-Luc Nancy (véase Nancy, 2002).
} 
Imaginar, escribir. La imaginación lingüística en J. Joyce y P. Celan...

mayorías, por agenciarse de recursos que hagan posible una inversión efectiva de las relaciones de dominación -o bien la simple desaparición de toda relación dominadordominado- la operación de fisuras en las lenguas dominantes visibilizan su precariedad: hacen posible estrategias de resistencia por parte de los dominados. Esto supone una forma nueva de encarar la lucha, pues la modernidad (binarista, como describía anteriormente) exigía una posición «negativa», esto es: presentaba al «dominador» y al «dominado» como un par de opuestos que se excluían mutuamente (exclusión esta que resultaba esencial para la legitimidad «moral»-además de política- de las insurrecciones del dominado) y desde dicha posición a este último no le quedaba más tarea que la de negar lo dado sin realmente poder explotar su capacidad de configurar nuevas positividades en el mundo ${ }^{17}$. La resistencia que menciono más arriba precisamente desplaza esta lógica binaria y entabla lo que, en términos bélicos, sería algo así como una «guerra de guerrillas» (pequeños focos de insurrección intestina que trabajan para desestabilizar un régimen dado). Es por ello que puede decirse que la creación de órdenes novedosos e insurgentes pasa, en el caso de estos escritores, por un deseo de inscribirse en la lengua del Amo no desde el lugar que ella les asigna (la del excluido, injuriado, oprimido, es decir lo negativo del dominador, los restos del orden social instituido) sino que «tomando por asalto» la lengua y la literatura quisieran hacer posible una desestabilización en el propio territorio del dominador, a fin de estallar sus categorías y desnaturalizar su uso de la palabra. Ya en Retrato del artista adolescente, Stephen Dedalus reflexionaba acerca de la inapropiabilidad del lenguaje:

El lenguaje en el que hablamos ha sido suyo antes que mío. ¡Qué diferentes resultan las palabras hogar, Cristo, cerveza, maestro, en mis labios y en los suyos! Yo no puedo pronunciar o escribir esas palabras sin inquietar mi espíritu. Su idioma, tan familiar y tan extraño, será siempre para mí un lenguaje adquirido. Yo no he creado esas palabras, ni las he puesto en uso. Mi voz se defiende de ellas. Mi alma se angustia entre las tinieblas de su idioma (Joyce, 1916: 187).

Aun, son tales palabras las que le permiten inscribirse también como «traidor»y hacer mella en el territorio del invasor.

\footnotetext{
${ }^{17}$ Por esta razón, los reproches que algunos amigos realizaban a Paul Celan por escribir en la lengua del Amo, pueden ser entendidos como el reproche de una modernidad que se negaba a ceder sus armas a estrategias de combate más fructíferas para los tiempos actuales. Celan comprendió, mucho antes que otros, que nuestra época (llámese capitalismo global integrado o globalización) se caracteriza por una insaciable necesidad de capturarlo todo, creando un mundo sin «afuera». Por eso, su lucha es desde adentro, y así debe asumir el riesgo de «contaminación» que supone la convivencia con el exterminador.
} 


\section{Incorporar el exceso}

Si bien Joyce y Celan resisten por igual, se ven llevados a transitar caminos distintos. En el escritor irlandés notamos una clara orientación hacia la proliferación de lo extraño en el interior de la lengua inglesa. Son el exceso y la exuberancia lo que hiere la lengua, no en una tentativa apropiadora sino antes bien a modo de armas en una revolución lingüística y literaria ${ }^{18}$. Leemos en Anna Livia Plurabelle (parte del célebre «experimento» joyceano llamado Finnegan`s Wake):

Pregúntale al Líctor Escriba o al Lector Leas de Garda Gruñe o a ese joven Hampón de la Manoplaporra. ¿De qué otro modo lo llaman? ¿Qu'appelle? Hughes Caput Enmierdaorejas. ¿O dónde nació o debajo de qué repillo perdrido lo encontraron, primogénito de los monstruogenitados, urgothlándose? (Joyce, 1939: 36).

La imaginación joyceana goza en la incorporación insaciable de unidades extrañas a la lengua base, en este caso el inglés británico, en una suerte de implosión de la unidad subyacente, lo cual da lugar a una apertura que implica contaminarse con todo lo que aquella lengua (la dominante) hubiera deseado excluir. Ahora bien, la ostentación de riqueza por parte del pobre conduce a un delirio que incluye (o desearía incluir) una multiplicidad de lenguas que hace imposible discernir cuál es la que predomina, con lo que la diferencia entre lo familiar y lo extranjero deviene imperceptible.

¡Oh crúentame todo lo que quiero saber, quiero yoírlo todo acerca, cuán alta en la esculera quedaba zurdosum cordadextro! Un cogeguiño luego de que cayeran los tapos (Joyce, 1939: 37).

Tal como sostiene J. Risset al estudiar la transposición al italiano de algunos fragmentos de Finnegan's Wake que realizó el propio Joyce, la escritura joyceana parece indicar una progresión que va del poliglotismo (la mezcla de diferentes lenguas e

\footnotetext{
${ }^{18}$ En «Palabra muerta habla. Cien años» (Kozak, 2006), Claudia Kozac se refiere a este tema tomando como punto de referencia la «Carta de Lord Chandos», en la cual estarían resumidas todas las condiciones que se detallaron aquí en torno a las problematizaciones del lenguaje y el yo. Allí, Kozac sugiere el reparto del campo contemporáneo según la modulación de dos maneras de hacer frente a las incertidumbres mencionadas: las estéticas del silencio y las de la proliferación. Escribe Kozac: «De la "Carta de lord Chandos" derivan prácticamente todas las modulaciones de las estéticas del silencio que atraviesan el siglo XX, y aun, muchas de las que se sustraen a ellas. Frente a las incertezas respecto del lenguaje, el yo y la comunidad -como diría Sloterdijk en una de sus mejores formulaciones, frente a la obsolescencia de esa cultura humanista que se podría entender como comunidad de amigos que se envían cartas; y en eso la carta de lord Chandos es desesperada porque es una carta al amigo pero también es la última- algunas de las líneas más pregnantes del arte del siglo XX, respondieron al vacío, con una "novedad" abierta en dos vías diferenciales pero complementarias. Por un lado, con estéticas del silencio: palabra muda, limitada, concentrada, pobre de recursos y, también, reiterada. De Kafka a Beckett, Duras o Celan. Por el otro, con estéticas de la proliferación, la creación de nuevos lenguajes, desde los delirios de la imaginación lingüística de Roussel a la palabra excesiva de Joyce o, incluso, a nuestro neobarroco. De Marinetti a las poéticas tecnológicas más contemporáneas que sacan a la literatura de sí misma por exceso de códigos (visuales, sonoros, genéticos). O sea: la limitación del lenguaje, su cercamiento, o su reinvención desde lo abierto. Transformación en ambos casos, con todo» (las negritas son mías).
} 
Imaginar, escribir. La imaginación lingüística en J. Joyce y P. Celan...

idiomas, principalmente en el Finnegan's Wake «original») al plurilingüismo (el reconocimiento de la pluralidad ínsita a una misma lengua, que por eso, no es Una) (véase Risset, 1984: 9). Este movimiento implicaría el señalamiento de que una lengua contiene o es en sí misma su propia extranjeridad o extrañeza, lo que confirmaría que la estrategia joyceana no trabaja tanto la mera «inversión» de las jerarquías (lo cual supondría la aceptación del binarismo antes mencionado) como la desjerarquización de los diferentes estratos de la lengua (altos, bajos) a través de su incorporación en un todo poético que ya no atiende a las necesidades ni de la comunicación ni de la retórica literaria (cfr. Risset, 1984: 9, 12). De allí que la imaginación joyceana no pueda ser atribuida a una interioridad personal en busca de expresión, sino que «Joyce» aparece como un operador de ciertas disposiciones imaginantes de la lengua que pugnan por emerger y autoconfigurarse.

Esta proliferación evoca en parte aquella Babel imaginada, la que hace de la comunicación y el acuerdo algo imposible; la evoca como si guardáramos una memoria de ella, como si fuera un estado del mundo olvidado que estuviéramos a punto de recordar. Surge el temor, la interrogación se hace posible en esta espacialización del miedo que es el abismo entre quien habla y la lengua que habla. La experiencia Joyce no puede más que hacer señas de la catástrofe: confusión que comienza borrando la diferenciación posible entre lenguas distintas - de la mano de un esmerado poliglotismo se arrasa con el idioma Inglés, que ya se ha hecho irreconocible- y que sin poder detener su propia multiplicidad -el plurilingüismo- estalla todo orden simbólico, todo código que haría posible -o al menos viable- un trabajo hermenéutico. La violencia que el escritor irlandés padece por ser tal (por ser expropiado de «su» lengua, por la imposición de sentidos y tradiciones desde un Inglés oficial) revierte sobre las reglas del lenguaje. Por ejemplo sobre sus unidades mínimas -las palabras- que ya no pueden ser pensadas como tales, los espacios ya no indican el fin de una y el comienzo de otra, se sintetizan nuevos vocablos a partir de un lenguaje que se pretende «oral»: baste mencionar «eterdredón», «turroaterrante», «hormigrano de oro». Notable es, también, la duplicación de las marcas: temáticas que se traducen en la grafía y borran los límites entre forma y contenido. En el caso de Anna Livia, capítulo donde dos lavanderas conversan a orillas del río Liffey, no sólo la escritura se encabalga al ritmo del correr de las aguas, sino que la disposición de las palabras crea un delta: 
La imposibilidad de captura impide la cristalización del proliferar joyceano en sistema, puesto que la «lengua» imaginada por Joyce no puede ser compartida, codificada, no vehicula sentidos. Por eso mismo, porque en rigor no crea una lengua o idioma nuevo como tal, la lengua Joyce no podría operar la violencia simbólica que toda lengua está destinada a realizar en la medida en que implica el forzamiento de unidades de sentido estables. Es la misma razón por la cual no tiene ningún sentido remontarse hasta el inicio del trabajo joyceano como si en aquel punto uno fuera a encontrarse con el origen puro de una lengua que luego se deformó: póstumamente, Joyce fue fiel a la genealogía descrita por Foucault, aquella que sólo puede reírse a carcajadas de su origen ${ }^{19}$.

De modo que podría decirse que, en Joyce, la imaginación lingüística da lugar a la aparición de una lengua que no tiene uso posible y que, queriendo decirlo todo, en verdad termina por no decir nada. Dicha convergencia entre el todo decir y el decir nada puede ser aquí un punto de paso apropiado para ir del escritor irlandés a Paul Celan.

\section{El muerto en la lengua}

Mientras en Joyce la necesidad de estallar la lengua del exterminador desde el interior se volcaba a la proliferación incesante de extrañezas que la llevaban a la implosión, en la poesía de Celan se traduce en un acallamiento de la lengua que, de algún modo, va debilitándola hasta que muere.

Celan responde, en el trato con la lengua, al horror de los campos de exterminio ${ }^{20}$. En la poesía celaniana, emerge una especie de «lengua muerta» cuyas palabras no sólo mueren sino que ellas mismas son cadáveres («Una palabra -tú sabes: / un cadáver» escribe en Nocturnamente enfaldados). El «judío» (que sería esta palabra-cadáver) no es

\footnotetext{
${ }^{19}$ La genealogía foucaultiana -inspirada en el trabajo de F. Nietzsche con el concepto de «origen» en filosofía- señala lo vano de todo gesto de «retorno» al origen en busca de una pureza supuestamente perdida con el paso del tiempo (cfr. Foucault, 1971)-. La «carcajada» originaria equivale a la ausencia de todo lo que occidente significa como fundamento. Derrida destaca la risa joyceana como operación de borramiento del nombre propio, que -de acuerdo al canon humanista- no sería otra cosa que el «fundamento» de un texto (cfr. Derrida, 1987).

${ }^{20}$ Desplazamiento «natural» si se acepta lo propuesto en la primera parte de este escrito (véase especialmente la sección 6 de «Imaginar»). Con este «responder» se hacen señas hacia la cuestión de la responsabilidad ante lo sucedido en los campos de exterminio nazis, responsabilidad asumida por los que han sobrevivido a ellos (incluso si no estuvieron en ningún campo), rara especie de responsabilidad que interpela también y sobre todo a las víctimas. Los avatares de la noción de «responsabilidad» -y los deberes asociados a ella- cuando desaparece la figura clásica que la sostenía (el individuo moderno) es abordada por una parte importante del pensamiento del siglo XX (tanto en filosofía como en literatura). Por poner un ejemplo, de alguien que siempre piensa en Celan: Cacciari (1997), esp. Cap. IV, secc. II. Sobre la falta de inocencia exigida por un pensamiento de la responsabilidad que va más allá de la ley, remito a Blanchot (1980).
} 
nombrado como tal, pues de algún modo su presencia ahí aun podría significar «alimentar» al exterminador. En cambio, Celan «mata de hambre» al exterminador en su propia lengua, consigue que su propia lengua ya no le dé de comer. O incluso le devuelve una lengua que no es más que alimento envenenado. A tal fin se orienta una sustracción del sentido y la palabra que recuerda al silencio (al problema de cómo escribir el silencio que se impone a través de la muerte). Si se piensa con Foucault (1963: 143) que la cercanía de la muerte excava «en el ser y en el presente el vacío a partir del cual y hacia el cual se habla», podemos imaginar que en la experiencia Celan, el vacío puja por traducirse en un silencio que no puede callarse, que nunca puede acabar encontrándose a sí mismo...

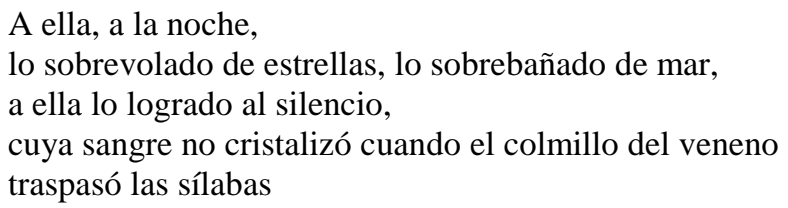

(de Argumentum e Silentio)

Este desfasaje del silencio consigo sería aquello que hace callar al exterminador y otorga al poeta el espacio en que podrá balbucear el horror de la muerte violenta. Lo que brilla, fulgor oscuro, en la poesía celaniana es la asunción de que el desastre ha devenido la condición de posibilidad de la palabra dicha («Cualquier palabra que tú hables - / la debes / al destrozo» se escucha en Cualquier piedra que levantes), pero siempre bajo la certeza de que no hay palabras que sean capaces de dar testimonio de la catástrofe -llamada, por condensación, Auschwitz-. De cualquier modo, persiste la obligación de ensayar el lenguaje silencioso que testimonie, toda vez que el poema está llamado a revelar la Verdad: «Habla / [...] / Dale a tu sentencia también el sentido / dale la sombra // Verdad habla quien habla sombra», en Habla también).

Se asiste, entonces, al despliegue de un sentido que sólo se halla en la «sombra» de lo dicho, es decir, en lo no-dicho (y hasta en lo que no es posible decir). De modo que, según esta lectura, el trato con el sentido y con la Verdad no es de mera renuncia (como si ya no hubiera uno o la otra), pues declarar sencillamente que hay horrores insensatos (los genocidios, por ejemplo) supondría exceptuar y exceptuarse de la interrogación abierta por la experiencia de los campos, supondría eludir la responsabilidad. Antes bien, en Celan se trata de un tema de «localización»: ¿en dónde están, dónde fueron a parar el sentido y la verdad que parecen ausentarse del mundo? Un modo de la respuesta se da bajo una aproximación inquietante: las palabras (con su 
Noelia Bill

sentido y su Verdad) han muerto pero, al igual que los muertos de los campos, no han desaparecido sino que han sido convertidos en ceniza.

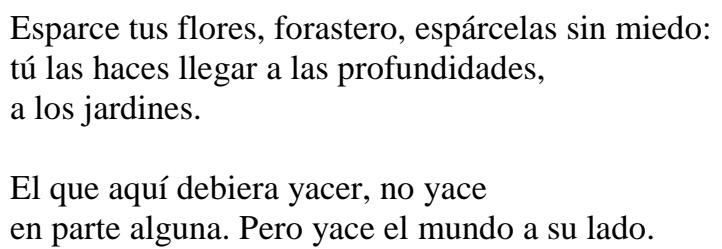

(de Cenotafio)

Como escribe Celan aquí, los muertos (los judíos, pero también el sentido y la Verdad) se ausentan del espacio que tradicionalmente les estaba reservado, su sepulcro está vacío ${ }^{21}$, pues -como se sabe- han sido reducidos a polvo, a ceniza ${ }^{22}$. Lejos de hacerlos desaparecer, esto los conecta con todo, la ceniza se transforma en el germen que se disemina por el mundo junto al cual yace. Este reparto de la semilla en un mundo que parece yerto ${ }^{23}$ encuentra una voz que lo justifique en Wolfsbohne:

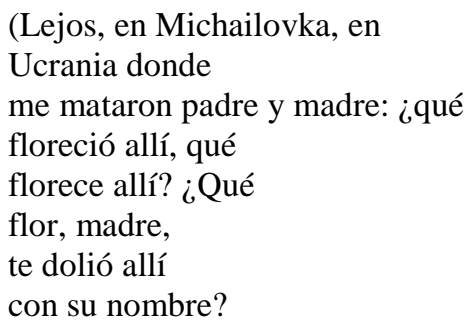

De modo que la pulverización de la lengua celaniana puede leerse como una operación de fragmentación que la abre a la multiplicación de conexiones de todo tipo con el mundo. La incisión de Celan en la lengua da lugar a una amorosa hostilidad hacia el lenguaje (Steiner, 1990: 193-195), lo que permitiría romper con la dominación al hacer evidente que la lengua no es apropiable. Pareciera, entonces, que Sentido y Verdad se esconden en la escritura, hallan su lugar de acogida en un poema de infinito espesor que es, de una vez, su morada y su tumba, donde viven y donde mueren. Pero también este mismo poema, dado que ha estallado en la lengua, los disemina por el

\footnotetext{
${ }^{21}$ El tema de la tumba vacía aparece de muchas formas en los poemas de Celan. Fuga de muerte ( «Grita que suene más dulce la muerte la muerte es un Maestro Alemán / grita más oscuro el tañido de los violines así subiréis como humo en el aire / así tendréis una fosa en las nubes no se yace allí estrecho»), Shibbólet («Junto con mis piedras, / crecidas en el llanto / detrás de las rejas...»), Tierra había en ellos $y$..., entre otros.

${ }^{22}$ En Al-químico se lee: «todos los nombres, todos los / nombres / quemados al par. Tanta / ceniza para bendecir...». En este poema el tema de la ceniza es claramente entramado en un trayecto que va de lo perdido a lo ganado, de la ceniza al oro, a través de un proceso de reconversión «al-química». Así, de algún modo, se responde a los proyectos científicos ligados al nazismo (los experimentos «químicos») con la mitología de la alquimia, siempre asociada al tocar mágico: por un toque mágico, el silencio se transforma en palabra que bendice una alianza, que es un modo de la resistencia.

${ }^{23}$ El tema de la fecundidad aparece también en La siembra de luz a libre viento...
} 
Tropelías. Revista de Teoría de la Literatura y Literatura Comparada, 19 (2013)

Imaginar, escribir. La imaginación lingüística en J. Joyce y P. Celan...

mundo, empuja con su imaginación las fronteras del silencio impuestas al mundo de los cuerpos y espacializa esos silencios que resultan ensordecedores, el adolecer de los nombres pulverizados en el aire.

Para concluir, invito a pensar con Maurice Blanchot que es ante la pérdida de las palabras habituales que el escritor -aceptación infinita- está en una relación íntima con las cosas, deviniendo entonces capaz de presentir un lenguaje (desconocido e imposible) que encierra el silencio que yace en el fondo de ellas. Es entonces que nos debemos inclinar hacia la imaginación de otras lenguas, incluso si ellas se ausentan o hacen silencio.

\section{Bibliografía}

Agamben, G. (1998): Homo Sacer III. Lo que queda de Auschwitz. El archivo y el testigo. Trad. de A. G. Cuspinera. Valencia, Pretextos, 2000.

Blanchot, M. (1994): L'Instant de ma mort. París, Fata Morgana. (1980): L’Écriture du desastre. París, Gallimard.

CACCIARI, M. (1980): Hombres Póstumos: la cultura vienesa del primer novecientos Trad. de F. Jarauta. Barcelona, Península, 1989.

(1997): El archipiélago. Figuras del otro en occidente. Trad. de M. C. Cragnolini. Buenos Aires, EUDEBA, 1999.

CAstoriadis, C. (1975): L'Institution imaginaire de la société. París, du Seuil.

CAsullo, N. (1990): Viena del 900, la remoción de lo moderno. Buenos Aires, Nueva Visión.

Celan, P. (1983): Obras completas. Trad. de J. L. Reina Palazón. Madrid, Trotta, $3^{\text {a }}$ ed., 2002.

Cragnolini, M. B. (1998): «Extrañas amistades. Una perspectiva nietzscheana de la philía desde la idea de constitución de la subjetividad como Zwischen», Perspectivas Nietzscheanas, VII/5-6, pp. 87-106.

- (2008): «El resto, entre Nietzsche y Derrida», en Cragnolini, M. B., ed., Por amor a Derrida. Buenos Aires, La Cebra, pp. 137-156.

Deleuze, G. (1969): Lógica del Sentido. Trad. de M. Morey y V. Molina. Buenos Aires, Paidós, 2005.

DERridA, J. (1986): Schibboleth. Pour Paul Celan. París, Galilée. (1987): «Dos palabras para Joyce», en Ulises Gramófono. Dos palabras para Joyce. Trad. M. Taruggi. Buenos Aires, 3 haches, 2002.

- (1996a): Monolinguisme de l'autre ou la prothèse d'origine. Paris, Galilée. (1996b): «Hablar por el otro», Diario de Poesía, 39, pp. 18-20. 
FoucAult, M. (1963): «El lenguaje al infinito», en De lenguaje y literatura. Trad. de I. Herrera. Barcelona, Paidós, 1997, pp. 143-155.

(1966): Las palabras y las cosas. Una arqueología de las ciencias humanas. Trad. de E. C. Frost. Buenos Aires, Siglo XXI, 1998.

- (1967): «Des espaces autres», Architecture, Mouvement, Continuité, 5, 1984, pp. 46-49.

(1971): «Nietzsche, la généalogie, l'histoire», en AA. VV., Hommage à Jean Hyppolite. Paris, P.U.F., pp. 145-172.

Habermas, J. (1981): Teoría de la Acción Comunicativa. Trad. de Manuel Jiménez Redondo. Madrid, Taurus, 1987, vol. I.

Hegel, G. W. F. (1807): Fenomenología del Espíritu. Trad. de W. Roces, México, FCE, 2000.

(1821): Principios de Filosofía del derecho. Trad. de J. L. Vermal, Barcelona, Edhasa, 1988.

JoyCE, J. (1916): Retrato del Artista Adolescente. Trad. de M. Martínez Sarmiento, México, Lectorum, 2002.

(1939): «Anna Livia Plurabelle». Trad. de L. Lamborghini, Revista Sitio, 2, Buenos Aires, 1982, pp. 35-37.

KozAK, C. ed. (2006): Deslindes. Ensayos sobre la literatura y sus límites en el siglo $X X$. Rosario, Beatriz Viterbo.

NANCY, J.-L. (2002): La création du monde ou la mondialisation. París, Galilée.

NiETZSCHE, F. (1873): Sobre verdad y mentira en sentido extramoral. Trad. de Luis ML. Valdés y Teresa Orduña. Madrid, Tecnos, 1998.

- (1889): Crepúsculo de los ídolos. Cómo se filosofa con el martillo. Trad. de A. Sánchez Pascual. Madrid, Alianza, 2001.

RisSeT, J. (1984): «Joyce translates Joyce», Comparative Criticism, 6, pp. 3-21.

Schulz, B. (1933): Madurar hacia la infancia. Trad. de E. Bortkiewicz Morawska. Madrid, Siruela, 2008.

Steiner, G., (1990): Gramáticas de la creación. Trad. de Andoni Alonso y Carmen Galán Rodríguez. Madrid, Siruela, 2001. 